\title{
Drivers Impacting Cobots Adoption in Manufacturing Context: A Qualitative Study
}

\author{
Ana C. Simões ${ }^{1(\bowtie)}$, António Lucas Soares ${ }^{1,2}$, and Ana C. Barros ${ }^{1}$ \\ ${ }^{1}$ INESC TEC, Rua Dr. Roberto Frias, 4200-465 Porto, Portugal \\ ana.c.simoes@inesctec.pt \\ ${ }^{2}$ Faculty of Engineering, University of Porto, Porto, Portugal
}

\begin{abstract}
Today's manufacturing environment is increasingly pressured to higher flexibility induced by uncertain production volumes as well as uncertain product lifetime. A way to improve productivity in a flexible production system is by using a safe and flexible cooperation between robot and operator. Therefore, manufacturing companies are experiencing an increase in humanrobot interactions and in the use of collaborative robots (cobots). To make full use of cobots, it is essential to understand the drivers for their adoption as well as how these drivers are aligned with the companies' strategic objectives. By means of in-depth interviews in six companies in Portugal and France, this study provides a comprehensive understanding of the drivers that influence the intent to adopt, or the effective adoption, of cobots and the alignment of these drivers with the strategic objectives of the company. Empirical results reveal "operational efficiency" and "ergonomics and human factors" concerns as important drivers in the adoption intent. In terms of strategic objectives, it was found that drivers are aligned with productivity and flexibility improvement as well as quality improvement strategic objectives. Understanding these drivers can help in motivating manufacturing companies to adopt cobots, in facilitating their adoption, and in reaping the benefits of this technology.
\end{abstract}

Keywords: Cobots $\cdot$ Adoption drivers $\cdot$ Strategy $\cdot$ Qualitative study

\section{Introduction}

In the last decades, the manufacturing ecosystem lived an unprecedented evolution of disruptive technologies, which has helped companies dealing with competitive pressures coming from product complexity, shorter product life cycles, change in demand towards more customized product, rapid time-to-market, cost pressure, increased international competition, etc. [1, 2]. To handle with these challenges, organizations continually seek for flexibility and adaptability of manufacturing processes, which require a close cooperation between the worker and the automated system [3]. Therefore, competitive levels in the manufacturing industry organizations are achieved investing in new technical developments (e.g. advances in robotics, artificial intelligence, and machine learning). The current flexible automation techniques, including flexible manufacturing systems (FMS), and reconfigurable manufacturing systems (RMS), lead to a recent trend in robotics that make use of the new generations of robots 
with the capability to directly assist humans [4]. Flexibility and adaptability of manufacturing processes require a close linkage between the worker (human) and the automated system.

Cobots are an advanced manufacturing technology primarily characterized by the fact that the robots' and workers' work zones overlap, creating a common workspace, without safety fencing or barriers in the manufacturing floor [5, 6]. According to a recent study carried out in German companies [6], humans and robots primarily work alongside each other in a form of coexistence (both interaction partners may have tasks to perform at the same time in the shared workspace, but they do not work simultaneously on the same product or component), an arrangement in which the new technology is very reliable. However, collaborative applications (human and robot working simultaneously on the same product or component) are virtually non-existent in production facilities at that time [6]. Cobots are designed for the assembly line worker to reduce ergonomics concerns that arise due to on-the-job physical and cognitive loading, while improving safety, quality, productivity and flexibility in plant operations [7, 8]. Then, a safe and flexible cooperation between machines and humans can be achieved, because it matches the strength and the efficiency of robots with the high degree of dexterity and the cognitive capabilities of humans achieving better productivity at the most flexible overall system [4, 9]. Furthermore, reducing the limits of robotic automation to allow a distribution of tasks between humans and robots enables the applicability of robots for industrial production. Humans and robots each take on the tasks for which they are best-suited, with frequent interaction and shared procedures [10]. However, the human must be kept in the centre of decision process in the production process for highly flexible assembly due to human's cognitive and sensomotoric advantage [4].

The interaction between human and robot improves complex assembly processes, particularly when a worker can guide a robot and the robot provides power support to the worker. The support provided by the robot to the worker in manufacturing processes are related to difficult, monotonous or physically demanding tasks [3]. Advances in sensors, actuators and data processing enable to improve the degree of assistance [3, 10]. The human should be part of production processes when he is needed, otherwise he can concentrate on other tasks to improve the overall system performance [4].

Decisions regarding automation in organizations are classified as process (technological) decisions. Nevertheless, this is a technical perspective since it does not take into consideration the integration of humans and technology and fails to explain the decisions for the selection of technological investments that support the company strategy [11]. With the growing implementation of cobots in the manufacturing processes, and thus the integration of humans and technology in order to achieve more efficient and robust production systems, the alignment between the automation decisions and the company' strategic objectives are critical for the company success [12]. The objective of this paper is to understand the drivers for the cobots adoption as well as how these drivers are aligned with the companies' strategic objectives. 


\section{Problem}

In light of the benefits and challenges of cobots, it is important to understand the drivers that influence the adoption of cobots in manufacturing companies, in order to facilitate a successful implementation of this technology. Current research within the field of human-robot interactions is suggesting that there are several challenges in the implementation of cobots (acceptance, security, etc.) that require further research [13]. This paper is contributing with empirical evidence to reduce this literature gap by researching important drivers that influence the adoption of cobots and the alignment of these drivers with the strategic objectives of the company. Hence, the research question for this paper is: What are the drivers that influence the intent to adopt, or the adoption, of cobots by manufacturing organizations, and how are they aligned with the companies' strategic objectives?

\section{Method}

The research reported in this paper is exploratory in nature and utilizes qualitative evidence. The purpose of this study is to identify and understand the drivers to adopt cobots in factories of multinational companies installed in Portugal and France. Given the novelty of this technology to manufacturing companies, this study considers that drivers conducting to cobots adoption can be better understood by examining the interpretations of managers $[14,15]$ in different function and industrial sectors, justifying a qualitative research approach.

Qualitative data were collected, providing rich insights for exploring, identifying, and understanding viewpoints regarding the adoption drivers, as well as offering the opportunity to understand deeply the topic and clarify misunderstanding aspects [16, 17]. Six companies were approached and agreed to participate to participate in the study. A total of thirteen interviews were conducted between February and May 2018, and had duration between 30 and $70 \mathrm{~min}$. Each interview was conducted in the Portuguese language, with the exception of one (C3I1) that was conducted in English language. The open-ended style of the interviews allowed the respondents to describe their opinions, experiences and ideas freely, without being limited to predefined concepts or models. Interviewees' characterization is presented in Table 1.

The audio files from the interviews were transcribed and MAXQDA (version 11.0) qualitative analysis software was used to analyze the interviews. A thematic and theory-driven analysis was adopted [18]. First, a subset of interview transcripts were analyzed (a) to develop an initial coding scheme for the pre-defined interview topics and (b) to identify topics in the transcripts that were not specifically queried by the interview guide [19]. After that, a structural coding was used to identify unanticipated topics that occur in the interview [18-20].

Construct validity has been addressed, first by using multiple sources of information [21]. While interviews constitute the primary source of information, some support information was collected in field notes (collected during the field visits to the facilities). In addition, the researchers themselves identified additional supporting documentation including materials located at the websites of the informants' organizations 
or in publications associated with the industry. Second, considering different perspectives constitutes an important type of triangulation of qualitative information sources [16]. Different perspectives were provided by the different key informants (see third column in Table 1). Finally, the chain of evidence, tracing the conclusions to the interview summary and to the interview transcripts was also maintained. According to Yin [21] these enhance the construct validity as well as the reliability of the research, thereby boosting its overall quality.

Table 1. Interviewees' characterization

\begin{tabular}{|c|c|c|c|}
\hline ID & $\begin{array}{l}\text { Industrial } \\
\text { sector }\end{array}$ & Function & $\begin{array}{l}\text { Duration } \\
(\mathrm{min})\end{array}$ \\
\hline C1I1 & $\begin{array}{l}\text { Security } \\
\text { system }\end{array}$ & $\begin{array}{l}\text { Industrial eng., process engineer and internal logistics } \\
\text { group leader; I4.0 project manager }\end{array}$ & 38 \\
\hline $\mathrm{C} 2 \mathrm{I} 1$ & Package & Divisional industrial director - packaging division & 60 \\
\hline C3I1 & Automotive & $\begin{array}{l}\text { Advanced manufacturing department in charge of } \\
\text { powertrain factory of future }\end{array}$ & 56 \\
\hline C4I1 & \multirow{5}{*}{$\begin{array}{l}\text { Automotive } \\
\text { components }\end{array}$} & West operations manager & 31 \\
\hline $\mathrm{C} 4 \mathrm{I} 2$ & & Process engineering manager & 36 \\
\hline $\mathrm{C} 4 \mathrm{I} 3$ & & Engineering and innovation director & 41 \\
\hline C4I4 & & Maintenance supervisor & 30 \\
\hline C4I5 & & Operations director & 43 \\
\hline C5I1 & \multirow[t]{2}{*}{ Automotive } & Lean management - continuous improvement & 52 \\
\hline C5I2 & & $\begin{array}{l}\text { Assistant manager - maintenance \& facility } \\
\text { management }\end{array}$ & $\begin{array}{l}\text { Written } \\
\text { form }\end{array}$ \\
\hline C6I1 & \multirow{3}{*}{$\begin{array}{l}\text { Automotive } \\
\text { components }\end{array}$} & Managing director & 65 \\
\hline C6I2 & & Maintenance supervisor & 32 \\
\hline C6I3 & & Process engineer & 70 \\
\hline
\end{tabular}

\section{Analysis and Results}

In the following sections the results of the interviews are presented. First, describing the companies in relation to the main aspects of this study, and then the drivers and their relationships with companies' strategic objectives. The data gathered from the interviews and by other sources of evidence provided the necessary information to understand the drivers that influence the intent to adopt, or the effective adoption, of cobots as well as to understand the alignment of these drivers with the strategic objectives of the company. 


\subsection{Companies Description}

Table 2 characterizes the companies for the purpose of this study.

Table 2. Companies' characterization

\begin{tabular}{|c|c|c|c|c|c|c|c|}
\hline Company & \begin{tabular}{|l|} 
Plant \\
location
\end{tabular} & Products & Headquarter & $\begin{array}{l}\text { Employees } \\
\text { (FTE) }\end{array}$ & $\begin{array}{l}\text { Turnover } \\
2017(\mathrm{M} €)\end{array}$ & $\begin{array}{l}\text { Classification } \\
(\text { FTE }>249)\end{array}$ & $\begin{array}{l}\text { Cobots } \\
\text { adoption }\end{array}$ \\
\hline $\mathrm{C} 1$ & Portugal & $\begin{array}{l}\text { Products related } \\
\text { to security } \\
\text { systems }\end{array}$ & Germany & 700 & 102 & Large & No \\
\hline $\mathrm{C} 2$ & Portugal & Plastic packages & Portugal & 950 & 142 & Large & No \\
\hline $\mathrm{C} 3$ & France & Cars & France & 170000 & 660000 & Large & No \\
\hline $\mathrm{C} 4$ & Portugal & $\begin{array}{l}\text { Automotive } \\
\text { plastic } \\
\text { components }\end{array}$ & Portugal & 3206 & 396 & Large & No \\
\hline $\mathrm{C} 5$ & Portugal & Trucks & Japan & 426 & 214 & Large & Yes \\
\hline C6 & Portugal & $\begin{array}{l}\text { Automotive } \\
\text { components }\end{array}$ & Germany & 422 & 110 & Large & No \\
\hline
\end{tabular}

In the last column, information related to the current situation related to cobots adoption: yes, if the company have cobots in its production process; no, if the company don't have yet cobots in its production process but intend to have them in the near future.

\subsection{Drivers}

During data analysis several drivers that influence the intent to adopt, or the effective adoption, of cobots were found in the empirical analysis. In the next sections these drivers are presented. The drivers will be presented and described considering, among other aspects, the frequency that participants referred this driver during the interviews. For the purpose of this study, a driver that was mentioned by all the participants is considered more important than one that was only mentioned, for example, by two participants.

\subsubsection{Operational Efficiency}

Operational efficiency was the driver more frequently mentioned by the interviewees and has been mentioned by all the 13 participants, which gives to this driver a great importance. The analysis of the empirical data allows for a detailed description of this important driver. Participants referred productivity improvement (efficiency improvement), quality improvement, flexibility improvement (efficient customization), workspace gains and complexity reduction as aspects (or "sub-drivers") to be considered in operational efficiency. Although, all these "sub-drivers" were mentioned in this study, the importance given by the participants was not the same for all. Thus, the sub-drivers mentioned with more frequency were, in this order, the productivity improvement (efficiency improvement), the quality improvement and the flexibility improvement (efficient customization). 
According to participants, the adoption of cobots leads to cost reduction, mainly due to wage cost reduction, which is viewed as an important contribute to improve efficiency. Additionally, the consistency improvement (through task repetition) is also considered as having an important contribution to improve quality (less errors) and consequently the productivity.

"We can say that our customer, in this case the holding company, has the driver Productivity. So, we [the subsidiary company] have to consider certain KPIs, or certain objectives, to accomplish. Therefore, this [productivity] is our driver." (C5I1)

The size of the cobots as well as the possibility that cobots have to execute tasks without fences, improving the available workspace, was also referred as a sub-driver that influences positively the operational efficiency. However, safety aspects related to the interaction between human workers and robots, distinct of this technology, were reflected as concerns of the participants of this study (C1I1, C3I1, C4I2, C5I1, C6I2 and C6I3). Although the numerous advantages of the collaborative robots, the participants C2I1, C3I1 C4I1, C4I2, C5I1 and C6I2 were aware of the limitations of this technology in terms of velocity (to execute the tasks) and impact. In order to achieve the safety requirements, the cobots execute the tasks with a low velocity (when compared to fenced traditional robots), which has a negative implication on productivity. According to the participants, risk assessment procedures and the application of safety and medical/biomechanical requirements must be considered in order to avoid injuries to the human workers (to keep any risk of injury to a low and acceptable level).

\subsubsection{Ergonomics and Human Factors}

Ergonomic and human factors concerns were the second most mentioned driver in this study. Almost all participants were unanimous referring that the adoption (or the intent) to adopt is firstly driven by ergonomic and human factors concerns. Regarding this driver, participants mentioned that the adoption of this technology would avoid assigning to human worker dangerous, repetitive and boring tasks. Additionally, cobots will support human worker giving power assistance and avoiding postural problems.

"I take it for granted that them [cobots] are coming to help, in repetitive operations, that in the ergonomic point of view are more difficult, or have more propensities to cause muscular and skeletal disorders etc., etc., I see them [cobots], in fact, as an asset." (C6I1).

Ergonomic improvements have strong links with human resources sustainability, according to the results of our study. The interviewee C5I1 mentioned that ergonomic optimisation is related to the advanced age of some the human workers in production lines:

"visual difficulties increase with age, they will also have locomotion difficulties, which means that these cobots, can also be a positive asset." (C6I3)

Other participants (C5I1, C4I2, C2I1) share the same concerns as C6I3. These participants look at these senior human workers as a valuable asset for the company, since they have the knowledge about the production process that young people don't have. The adoption of cobots can be driven by the desire to maintain that senior workers as much time as possible giving them the best work conditions. These 
participants see in the cobots the support that these senior workers need to execute their tasks better and with quality.

For participant C2I1, the cobot adoption is driven by the need to balance the demand and supply labour needs in certain geographic regions. Additionally, the expectations and experience of younger and older human workers also need to be considered.

"On the one hand, people who come to the plant [for the first time] don't adapt themselves to the conditions that plant offer, [the plant] is unattractive for them, on the other hand the people in the plant have difficulties in the adoption of new technologies and to the interfaces." (C2I1)

\subsubsection{Industrial Innovation Context}

The participants refer innovation as an important driver to the adoption of cobots. Eight participants mentioned this driver. For C5I1 the possibility to be the first company in the group to implement in the production process a cobot is considered an important driver, since they want to be considered an innovative company in their group. C6I3 also referred the importance of implement new technologies in the production process, since according to him can be a competitive advantage. C1I1, C6I1 and C3I1 also shared the same opinion.

"Another external factor is the need to show [for those outside the company] that we didn't freeze in time regarding the technological development, that we search for the best for what we want to produce, and at the same time is the best to our customers." (C6I1)

Other participants see the industrial context, in this case the automotive industry, as a driver to adopt new technologies. The technology progress as well as the investments on the development of new technologies made by companies in this sector is considered by $\mathrm{C} 4 \mathrm{I} 4, \mathrm{C} 3 \mathrm{I} 1$ and $\mathrm{C} 2 \mathrm{I} 1$ as one of the most relevant drivers.

\subsection{Alignment with Company Strategy}

The empirical results show that the companies follow three main strategic objectives for the participants companies: improve productivity, improve quality and promote innovation.

Almost all companies' participants in this study referred productivity and efficiency as the most important strategic objective. It is notorious the alignment of this objective with the driver "Operational efficiency". Several aspects mentioned related to this driver contribute to improve the efficiency and productivity, such as improving flexibility (batch sizes and cobot functions), reducing labour costs and reducing non-quality costs.

As a strategic objective, the participants view quality improvement in two perspectives: quality of working life (satisfaction) of the workers and the final quality of the product. Therefore, the driver "ergonomics and human factors" is aligned with both objectives, since it improves quality in the perspective of the satisfaction of the human workers as well as improves the quality of products themselves.

"The other strategy is to guarantee that the operator has other [better] quality is the work place, which he doesn't have today." (C6I3) 
Participants from companies C2, C4, C5 and C6 put great emphasis on strategic objectives related to quality of working life and these objectives are very aligned with the driver "ergonomics and human factors".

Additionally, the quality improvement by reducing non-quality products (with direct implications on cost) as well as a better satisfaction of the customer is mentioned in this study by ten participants, as an important strategic objective and is aligned with operational efficiency driver.

“(...) extensive assemblies, where the probability to fail is considerable for the operator, the probability to fail in assembling a small part is high, the existence of a cobot can eliminate this risk of fail, it is a win-win situation." (C1I1)

Finally, promoting innovation is the third strategic objective mentioned in this study. According to the results, this objective is aligned with the previous mentioned driver with the same name, "Industrial innovation context". For all companies participating in this study the implementation of new technologies (industry 4.0 technologies) in their production processes is part of the strategy.

The adoption of this kind of technology meets the group strategy, there is a group strategy regarding the adoption of Industry 4.0 technologies. So, this means that there is clearly a vision." (C6I3)

C4I2 mentioned that the innovation is a strategic goal always present, and the adoption of this new technology, namely automation technology, is the natural path of the company. For C4I3 the innovation, is indirectly linked to the results (in terms of processes efficiency), since new technologies when adopted improved these results.

\section{Conclusion}

Cobots are considered new technologies with important benefits for companies. The results of this study reveal that operational efficiency, ergonomics and human factors, and industrial innovation context are relevant drivers with influence on the intent to adopt, or the adoption, of cobots. It was possible to conclude that there is an alignment of these drivers with the strategic objectives of the company, since these drivers are reflected in the companies' strategic objectives. However, challenges related to their implementation, are reflected in some concerns expressed by company managers, mainly the safety aspect. The priority is to guarantee worker safety while simultaneously avoiding intermittent disruption of the robot's work. Additionally, the acceptance of this technology by human workers, that have to share the same workspace with cobots, was also pointed as a challenge by the participants. Clearly, the study reported in this paper is based on the Portuguese and French contexts, and thus, it may not be readily generalizable beyond this study. Further research is required, both in Portugal and in other countries and industries to ensure generalizability. Future research should consolidate these results with other companies in different industries and in different countries. 
Acknowledgments. This work was supported by Portugal 2020 project "DM4Manufacturing Aligning manufacturing decision making with advanced manufacturing technologies", POCI-010145-FEDER-016418, financed by UE/FEDER through the program COMPETE2020 and by the Project "TEC4Growth - Pervasive Intelligence, Enhancers and Proofs of Concept with Industrial Impact", NORTE-01-0145-FEDER-000020, financed by the North Portugal Regional Operational Programme (NORTE 2020), under the PORTUGAL 2020 Partnership Agreement, and through the European Regional Development Fund (ERDF).

\section{References}

1. Brettel, M., et al.: How virtualization, decentralization and network building change the manufacturing landscape: an industry 4.0 perspective. Int. J. Mech. Ind. Sci. Eng. 8(1), $37-$ 44 (2014)

2. De Carolis, A., Tavola, G., Taisch, M.: Cyber-physical systems in manufacturing: future trends and research priorities. In: 21st Summer School Francesco Turco 2016, Italy (2016)

3. Krüger, J., Lien, T.K., Verl, A.: Cooperation of human and machines in assembly lines. CIRP Ann. - Manuf. Technol. 58(2), 628-6469 (2009)

4. Lenz, C., Knoll. A.: Mechanisms and capabilities for human robot collaboration. In: IEEE International Symposium on Robot and Human Interactive Communication, Edinburgh, UK. IEEE (2014)

5. Colgate, J.E., et al.: Cobots: robots for collaboration with human operators. In: Proceedings of the International Mechanical Engineering Congress and Exhibition, Atlanta, USA (1996)

6. Bauer, W., et al.: Lightweight robots in manual assembly best to start simply. FrauenhoferInstitut für Arbeitswirtschaft und Organisation IAO, Stuttgart. (2016)

7. Akella, P., et al.: Cobots for the automobile assembly line. In: International Conference on Robotics and Automation, Detroit, MI, USA. IEEE (1999)

8. Calitz, A.P., Poisat, P., Cullen, M.: The future African workplace: the use of collaborative robots in manufacturing. SA J. Hum. Resour. Manag. 15(1), 1-11 (2017)

9. Hägele, M., Schaaf, W., Helms, E.: Robot assistants at manual workplaces: effective cooperation and safety aspects. In: 33rd ISR (International Symposium on Robotics) (2002)

10. Fryman, J., Matthias, B.: Safety of industrial robots: from conventional to collaborative applications. In: Robotics, Munich, German. VDE (2012)

11. Hill, T.: Manufacturing Strategy: Text and Cases, 2nd edn. Palgrave Macmillan, Basingstoke (2000)

12. Lindström, V., Winroth, M.: Aligning manufacturing strategy and levels of automation: a case study. J. Eng. Tech. Manag. 27(3-4), 148-159 (2010)

13. Djuric, A.M., Urbanic, R., Rickli, J.: A framework for collaborative robot (CoBot) integration in advanced manufacturing systems. SAE Int. J. Mater. Manuf. 9(2), 457-464 (2016)

14. Gray, D.E.: Doing Research in the Real World, 2nd edn. Sage, Thousand Oaks (2009)

15. Flick, U., von Kardoff, E., Steinke, I.: What is qualitative research? An introduction to the field. In: Flick, U., von Kardoff, E., Steinke, I. (eds.) A Companion to Qualitative Research. Sage, Thousand Oaks (2004)

16. Patton, M.Q.: Qualitative Research \& Evaluation Methods, 3rd edn. Sage Publications, Incorporated, Thousand Oaks (2002)

17. Mason, J.: Qualitative Researching, 2nd edn. Sage, Thousand Oaks (2002) 
18. Namey, E., et al.: Data reduction techniques for large qualitative data sets. In: Guest, G., MacQueen, K. (eds.) Handbook for Team-Based Qualitative Research, pp. 137-162. AltaMira Press, Lanham (2008)

19. MacQueen, K.M., et al.: Codebook development for team-based qualitative analysis. Cult. Anthropol. Methods 10(2), 31-36 (1998)

20. Saldaña, J., The Coding Manual for Qualitative Researchers (2009)

21. Yin, R.K.: Case Study Research: Design and Methods, 4th edn. SAGE Publications, London (2009) 